\title{
Evaluation of Plasma D-Dimer as an Initial Diagnostic Biomarker Incerebral Venous Thrombosis- A Prospective Cross Sectional Study.
}

\author{
Dr.A.Akila. M.D1, Dr.M.Ananthi. M.D2, Dr.V.Manojkumar3. \\ 1. Assistant Professor, Department of GeneralMedicine, Coimbatore Medical college \& Hospital, Coimbatore. \\ 2. Assistant Professor, Department of General Medicine, Manakula Vinayagar medical college,Pondicherry. \\ ${ }^{3}$. Junior resident, Department of General Medicine, Coimbatore Medical College \& Hospital, Coimbatore.
}

\begin{abstract}
Cerebral venous thrombosis (CVT) is a life threatening condition with varied clinical presentations. It is mainly a diagnosis by means of radiological tool. CT Brain is the initial investigation of choice. It may be normal in 30-40\% of the population. MRI with MRV is the gold standard for the diagnosis of CVT. D Dimer is a product of fibrinolysis which is usually used as an exclusion marker of venous thrombosis.

Our study aims to analyse the usefulness of D Dimer as an initial diagnostic marker in CVT.

Methodology: The patients diagnosed to have CVT by MRI in Coimbatore Medical College above 18 yrs of age are included in the study. A total of 50 patients are included in the study. After confirming the diagnosis, blood samples were drawn, plasma separated and sent to laboratory. D Dimer tests were measured by ELISA test. A value of more than $500 \mathrm{ng} / \mathrm{ml}$ was considered positive. All the tests were entered in a data collection sheet in an Excel format and analysed using SPSS software.

Results: Out of the 50 patients, 28 were females, and 28 were above 35 yrs. The common presenting symptom is headache (96\%), followed by seizures, altered sensorium, with papilledema (60\%). The most common sinus involved is superior sagittal sinus (70\%) followed by sigmoid and transverse sinus. CT Brain was normal in 50 $\%$ of the patients. Inherited thrombophilias contribute to $23 \% . D$ Dimer was positive in $78 \%$ of the study population. D Dimer and MRV has a highly significant correlation (0.034). D Dimer and onset of symptoms have a very high significant value of 0.000 .

Conclusion: D Dimer can be used as an initial diagnostic bio marker in CVT as there is a significant association with MRI .If patients present very early D Dimer is a highly reliable investigation. Further studies needed for the supportive evidence.

Keywords: Cerebral Venous Thrombosis, D Dimer, Magnetic Resonance Imaging
\end{abstract}

\section{Introduction}

Cerebral venous thrombosis (CVT) is a common cerebrovascular accident due to a multitude of causes. The diagnosis is often missed because of its varied clinical presentation. The etiological factors are even more heterogenous making cerebral venous thrombosisa unique clinical entity. The disease can occur denova as the first manifestation,or can overlap on another co existing clinical problem. The occurrence of thrombus depends upon the site, duration, extent and the rapidity with which the thrombus occurs. The presentation of CVT is variable in the form of convulsions, increased intra cranial tension, meningeal infection or hemorrhage.

Although CVT has its varied presentation, headache is the most common symptom. ${ }^{1}$ The diagnosis requires a high index of suspicion. CT Scan may show direct and indirect signs.At times CT may be normal.MRI with MRV is the diagnostic investigation of choice.The early diagnosis of this condition will prevent the mortality and morbidity of the society as it is treatable condition.

Plasma D-Dimer (fibrin degradation product) may be a good investigation for the diagnosis of CVT. D Dimer has a very high negative predictive value of ruling out venous thrombo embolism in DVT and pulmonary embolism.Several studies been done for analyzing the value of D-Dimer in excluding cerebral venous thrombosis. This study aims to evaluate the usefulness of plasma D-Dimer as an initial diagnostic biomarker for the diagnosis of cerebral venous thrombosis.

\section{Aims Of The Study}

1. To estimate the level of plasma D-DIMER and its significance in diagnosing Cerebral Venous Thrombosis.

2. To correlate the relationship between plasma D-DIMER and MRI BRAINin diagnosing Cerebral Venous Thrombosis.

3. To evaluate the diagnostic value of negative D-DIMER in ruling out Cerebral Venous Thrombosis. 


\section{Methodology}

Source of Study : Patients diagnosed to have cerebral venous thrombosis at Coimbatore Medicalcollege.

Design of Study : Cross sectional Study

Period of Study : AUGUST 2016 - FEBRUARY 2017

Sample Size $\quad: 50$

\section{Inclusion Criteria:}

- Patients who are diagnosed to have cerebral venous thrombosis by means of MRI and MRV in Coimbatore medical college within 30 days of symptoms onset, not started on anticoagulation.

- Age above 18 yrs.

\section{Exclusion Criteria:}

- Pregnancy

- Puerperium upto 4 weeks

- Arterial stroke within past 3 months

- Pulmonary embolism or Deep vein thrombosis

- Head injury within past 3 months

- Rheumatoid Arthritis

- Intra cerebral mass lesion

The patients diagnosed to have cerebral venous thrombosis confirmed with MRI BRAIN during the study period were included.After getting informed written consent,careful medical history was obtained including clinical features,precipitating risk factors,family history .All patients were subjected to meticulous general and neurological examination .Patients were subjected to MRI BRAIN with Venography on a 1.5 Tesla machine. After confirming the diagnosis of CVT by MRI and MRV, blood samples were drawn, plasma was separated, frozen at $-80 \mathrm{C}$ and sent to the laboratory. A basic hematological work up including complete blood counts, peripheral blood smear, ESR, PT/APTT were done.D-Dimer tests were measured by using a conventional ELISA Test.A value of more than $500 \mathrm{ng} / \mathrm{ml}$ were considered positive tests.In order to find out the etiology of CVT, dsDNA, APLA, serum homocysteine was done .

\section{Statistical Analysis}

All the dates were entered in a data collection sheet in an Excel format and analysed using SPSS Software.Numerical values were reported using mean and standard deviation or median.categorical values are reported using number and percentages.probability value (p) value less than 0.05 was considered a statistically significant.

\section{Observation And Results}

During the 12 month study period, a total of 50 patients were studied for finding out the usefulness of D DIMER as an initial diagnostic bio marker in CVT.

\section{Sex Distribution:}

Table 5: Sex distribution among the study population

\begin{tabular}{|l|l|l|}
\hline SEX & Frequency & Percent (\%) \\
\hline Female & 28 & 56.0 \\
\hline Male & 22 & 44.0 \\
\hline Total & 50 & 100.0 \\
\hline
\end{tabular}

Among the 50 patients, 28 were females (56\%) and 22 were males (44\%). The ratio of female: male was 1.3:1.

\section{Age Distribution:}

Table 6: Age distribution among the study population

\begin{tabular}{|l|l|l|}
\hline AGE GROUP & Frequency & Percentage (\%) \\
\hline Above 35 yrs & 28 & 56.0 \\
\hline Upto 35 yrs & 22 & 44.0 \\
\hline Total & 50 & 100.0 \\
\hline
\end{tabular}

The age of the patients comes under 2 categories. The majority of them are above 35 yrs $(56 \%)$.The patients below 35 yrs are around $44 \%$.

Socioeconomic Status: Majority of the cases were within the low socioeconomic status $(64.4 \%)$, the rest belonged to the middle socioeconomic status. 
Evaluation Of Plasma D-Dimer As An Initial Diagnostic Biomarker Incerebral Venous Thrombos...

\section{Symptomatology and Signs:}

Table 7: Clinical Profile of Headache

\begin{tabular}{|l|l|l|l|l|l|}
\hline Symptoms and signs & YES & NO & Total & $\begin{array}{l}\text { Percentage of patients having signs and } \\
\text { symptoms }\end{array}$ \\
\hline HEADACHE & 48 & 2 & 50 & $96 \%$ & \\
\hline CONVULSIONS & 17 & 33 & 50 & $34 \%$ & \\
\hline VOMITING & 31 & 19 & 50 & $62 \%$ & \\
\hline LOSS OF CONSCIOUSNESS & 13 & 37 & 50 & $26 \%$ & \\
\hline CRANIAL NERVE & 11 & 39 & 50 & $22 \%$ & \\
INVOLVEMENT & & & & & \\
\hline FEVER & 14 & 36 & 50 & $28 \%$ & \\
\hline PAPILLOEDEMA & 30 & 20 & 50 & $60 \%$ \\
FOCAL DEFICITS & 20 & 30 & 50 & $40 \%$ & \\
\hline
\end{tabular}

\section{Sinuses involved}

\begin{tabular}{|l|l|l|}
\hline SINUS INVOLVED & NUMBER & PERCENTAGE \\
\hline Superior Sagittal sinus & 35 & $70 \%$ \\
\hline Transverse sinus & 20 & $40 \%$ \\
\hline Sigmoid sinus & 25 & $50 \%$ \\
\hline Straight sinus & 6 & $12 \%$ \\
\hline Cortical veins & 12 & $24 \%$ \\
\hline
\end{tabular}

In our study, most common sinus involved is superior sagital sinus (70\%), followed by sigmoid sinus (50\%), transverse sinus $(40 \%)$, cortical veins $(24 \%)$ and straight sinus $(12 \%)$

\section{Investigations:}

\begin{tabular}{|l|l|l|l|l|}
\hline INVESTIGATIONS & RESULTS & FREQUENCY & PERCENTAGE & TOTAL \\
\hline D-DIMER & POSITIVE & 39 & 78 & 50 \\
& NEGATIVE & 11 & 22 & 50 \\
\hline Ds-DNA & POSITIVE & 7 & 14 & \\
& NEGATIVE & 43 & 86 & 50 \\
\hline APLA & POSITIVE & 7 & 14 & 50 \\
& NEGATIVE & 43 & 86 & \\
\hline HYPER- & POSITIVE & 18 & 30 & 50 \\
HOMOCYSTEINEMIA & NEGATIVE & 35 & 70 & 50 \\
\hline NEUROIMAGING & ABNORMAL & 25 & 50 & \\
STUDIES & NORMAL & 25 &
\end{tabular}

Table 21: Onset Range

\begin{tabular}{|l|l|l|}
\hline ONSET & FREQUENCY & \% \\
\hline UPTO 7 DAYS & 40 & 80.0 \\
\hline ABOVE 7 DAYS & 10 & 20.0 \\
\hline TOTAL & 50 & 100.0 \\
\hline
\end{tabular}

Out of 50 patients, 40 patients $(80 \%)$ of the study population had an early onset of symptoms within a period of 7 day.

Table 22: Correlation of D Dimer and ds DNA

\begin{tabular}{|c|c|c|c|c|c|c|}
\hline & \multicolumn{2}{|l|}{ D DIMER } & \multirow[t]{2}{*}{ Total } & \multirow{8}{*}{$\begin{array}{l}\text { P Value } \\
0.595\end{array}$} \\
\hline & & & NEGATIVE & POSITIVE & & \\
\hline \multirow{4}{*}{$\begin{array}{l}\text { ds } \\
\text { DNA }\end{array}$} & \multirow[t]{2}{*}{ NEGATIVE } & Count & 10 & 33 & 43 & \\
\hline & & $\%$ within D DIMER & $90.9 \%$ & $84.6 \%$ & $86.0 \%$ & \\
\hline & \multirow[t]{2}{*}{ POSITIVE } & Count & 1 & 6 & 7 & \\
\hline & & $\%$ within D DIMER & $9.1 \%$ & $15.4 \%$ & $14.0 \%$ & \\
\hline \multirow{2}{*}{\multicolumn{2}{|c|}{ Total }} & Count & 11 & 39 & 50 & \\
\hline & & $\%$ within D DIMER & $100.0 \%$ & $100.0 \%$ & $100.0 \%$ & \\
\hline
\end{tabular}

Out of the 7 Ds DNA positive cases, 6 cases are found to have D DIMER positive. Out of the 43 negative ds DNA Patients 33 have D Dimer positivity and 10 D Dimer negativity.There is no significant positive correlation with ds DNA and D Dimer in this study.

Table 23: Correlation of APLA and D Dimer

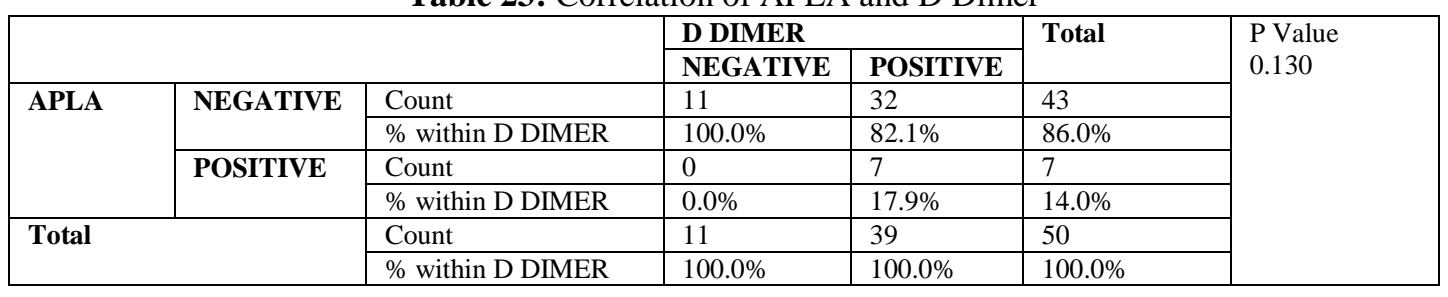


Out of the 7 positive case of APLA, all the 7 positive cases had D Dimer positivity and out of the 43 negative APLA , 32 had D Dimer positive and 11 had D Dimer negative. There is no significant positive correlation with D Dimer and APLA in this study.

Table 24: Correlation of D Dimer and Homocysteine

\begin{tabular}{|c|c|c|c|c|c|c|}
\hline & \multicolumn{2}{|l|}{ D DIMER } & \multirow[t]{2}{*}{ Total } & \multirow{8}{*}{$\begin{array}{l}\text { P Value } \\
0.087\end{array}$} \\
\hline & & & NEGATIVE & POSITIVE & & \\
\hline \multirow[t]{4}{*}{ HOMO } & \multirow[t]{2}{*}{ NEGATIVE } & Count & 10 & 25 & 35 & \\
\hline & & $\%$ within D DIMER & $90.9 \%$ & $64.1 \%$ & $70.0 \%$ & \\
\hline & \multirow{2}{*}{ POSITIVE } & Count & 1 & 14 & 15 & \\
\hline & & $\%$ within D DIMER & $9.1 \%$ & $35.9 \%$ & $30.0 \%$ & \\
\hline \multirow{2}{*}{\multicolumn{2}{|c|}{ Total }} & Count & 11 & 39 & 50 & \\
\hline & & $\%$ within D DIMER & $100.0 \%$ & $100.0 \%$ & $100.0 \%$ & \\
\hline
\end{tabular}

In this study, 15 patients have elevated homocysteine levels.Out of these 14 had D Dimer positive.Out of the 35 negative cases 25 patients had D Dimer positive. There is no significant positive correlation between $\mathrm{D}$ Dimer and homocysteine in this study.

Table 25: Correlation of D Dimer With CT Brain

\begin{tabular}{|c|c|c|c|c|c|c|}
\hline & & & \multicolumn{2}{|l|}{ D DIMER } & \multirow[t]{2}{*}{ Total } & \multirow{8}{*}{ HIGHLY SIGNIFICANT } \\
\hline & & & NEGATIVE & POSITIVE & & \\
\hline \multirow[t]{4}{*}{ CT } & \multirow[t]{2}{*}{ ABNORMAL } & Count & 1 & 24 & 25 & \\
\hline & & \% within D DIMER & $9.1 \%$ & $61.5 \%$ & $50.0 \%$ & \\
\hline & \multirow[t]{2}{*}{ NORMAL } & Count & 10 & 15 & 25 & \\
\hline & & \% within D DIMER & $90.9 \%$ & $38.5 \%$ & $50.0 \%$ & \\
\hline \multirow{2}{*}{\multicolumn{2}{|c|}{ Total }} & Count & 11 & 39 & 50 & \\
\hline & & $\%$ within D DIMER & $100.0 \%$ & $100.0 \%$ & $100.0 \%$ & \\
\hline
\end{tabular}

The D Dimer and CT brain has a strong positive correlation in our study.in our study, there is positive findings in $50 \%$ of the study group.In the 25 patients, out of the 25 negative CT patients ,24 patients had positive D Dimer. This implies that eventhough CT may be normal, D Dimer is elevated in majority of population .So D Dimer can be used as an initial diagnostic bio marker in diagnosing CVT.

Table 26: Correlation of D Dimer and Onset of Symptoms

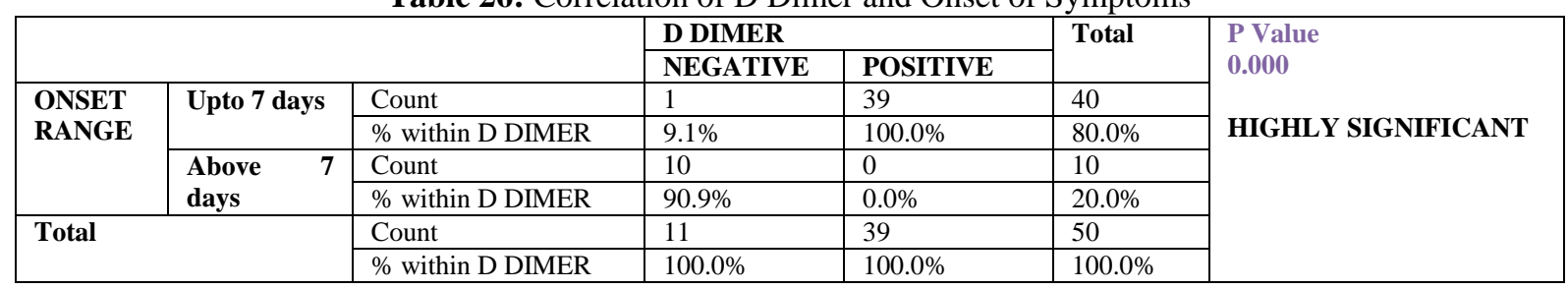

The D Dimer was positive in patients who presented early .Out of the 40 D Dimer positive patients, 39 patients presented to us within 7 days. There is a significant positive correlation between D Dimer and onset of symptoms in our study. So D Dimer can be used as a diagnostic marker in CVT.

Table 27: Correlation of D Dimer with MRI/MRV:

\begin{tabular}{|c|c|c|c|c|c|c|}
\hline & & & \multicolumn{2}{|l|}{ D DIMER } & \multirow[b]{2}{*}{ TOTAL } & \multirow{7}{*}{$\begin{array}{l}\text { P VALUE - } 0.034 \\
\text { HIGHLY } \\
\text { SIGNIFICANT }\end{array}$} \\
\hline & & & NEGATIVE & POSITIVE & & \\
\hline \multirow{4}{*}{ MRV } & \multirow{4}{*}{$\begin{array}{l}\text { No of } \\
\text { Sinuses } \\
\text { involved }\end{array}$} & 1 & 7 & 12 & 19 & \\
\hline & & 2 & 4 & 8 & 12 & \\
\hline & & 3 & 0 & 15 & 15 & \\
\hline & & 4 & 0 & 4 & 4 & \\
\hline \multicolumn{3}{|c|}{ TOTAL } & 11 & 39 & 50 & \\
\hline
\end{tabular}

In this the correlation between MRV and D DIMER is highly significant if there is a single sinus involvement the positivity of $\mathrm{d}$ dimer is less. When the number of sinus involvement is more, the positivity of $\mathrm{d}$ dimer is high.since d dimer is positive in most of the sinus involvement, it can be used as an initial diagnostic bio marker in CVT . 
Area Under The Curve - Roc Curve

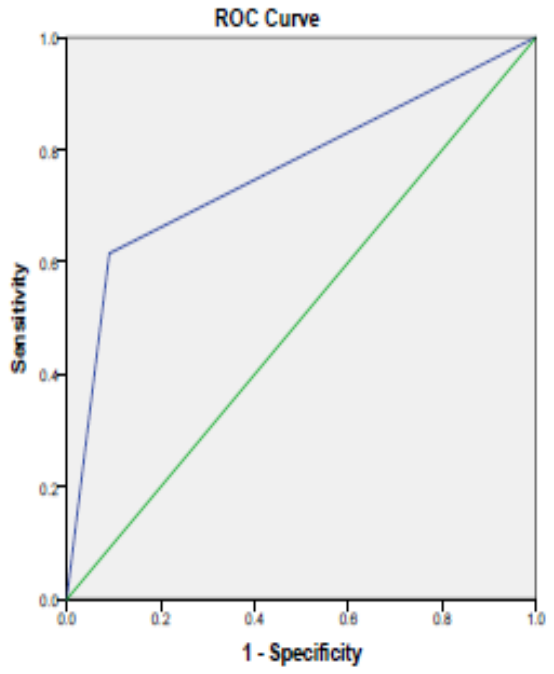

Disgonal zegments are produced by tees.

Coordinates of the Curve

Test Result Variable(s): CT
\begin{tabular}{|r|r|r|}
\hline Positive if & & \\
Greater Than & & \\
or Equal To & & \\
\hline-1.00 & 1.000 & 1.000 \\
.50 & .615 & .091 \\
2.00 & .000 & .000 \\
\hline
\end{tabular}

The values in the ROC curve indicate that there is a positive correlation between the variables mentioned as shown in the table and curve above.

\section{Summary}

This study was undertaken to study the usefulness of D Dimer as an initial diagnostic bio marker in cerebral venous thrombosis. A total of 50 patients were studied over a period of one year. The salient features in our study are highlighted below:

1. The mean age of presentation in our study is 34.82 .

2. There is a slight female preponderance in our study .The sex ratio was $1.3: 1$.

3. The most common presenting feature is headache $(96 \%)$ though non specific, followed by seizures (34\%),altered sensorium (26\%). The most common sign is papilledema (60\%) followed by focal deficits $(40 \%)$

4. Isolated headache has a negative D Dimer value

5. The commonest sinus involved is superior sagittal sinus (70\%),followed by sigmoid and transverse sinus.Most of the patients had more than one sinus involvement.

6. CT Brain was normal in $50 \%$ of the patients.

7. Inherited Thrombophilias contribute to around $23 \%$ of patients with CVT.The most common in our study is Hyperhomocystenemia.

8. No cause is identified in 14 patients.

9. D Dimer was positive in $78 \%$ of the patients with CVT.D Dimer has a high sensitivity when presented early

10. D Dimer and MRV has a significant correlation. So in early diagnosis of CVT, D Dimer can be used as a diagnostic tool.MRI / MRV being a superior modality than CT, should be used in patients suspected of having CVT. 


\section{Conclusion}

- Positive D Dimer test with high sensitivity and negative predictive value may be a useful diagnostic modality in suspected CVT patients

- Normal value of D Dimer makes the diagnosis of CVT unlikely

- MRI should preferably be done only in patients with positive D Dimer test and highly suspected cases.

- Further studies are needed to highlight the importance of D Dimer in CVT.

\section{Bibliography}

[1]. Bousser MG, Chiras J, Bones J, Castaigne P .Cerebral venous thrombosis. A review of 38 cases .Stroke 1985; 16: 199-213.

[2]. Ribes MF. Des recherché faites sur la phle bite .Re vue Medicale Francaise et Etrangere et. Journal de clinique de 1 Hotel - Dieu ET de la Charite de Paris 1825; 3:5-41.

[3]. Aberombei J. Superior Sagittal Thrombosis in puerperium .In pathological and practical Researches of the Brain and spinal cord, Edinburgh: John Carrfare and Sons Publishers; 1828.

[4]. Stam J. Thrombosis of the Cerebral Veins and Sinuses. New England Journal of Medicine 2005; 352; $1791-8$.

[5]. Bounameaux H, de Moerlooh P, Peureiu A, Reber G. Plasma measurement of D Dimer as a diagnostic tool in suspected venous thromboembolism. An overview Thromb Hemostat .1954; 71:1-6.

[6]. Barnett HJM, Hyland HH, Non infective intracranial venous thrombosis, Brain 1953; 76:36-45.

[7]. Wilteterdink L, Aston JD, Cerebral ischemia in "Neurology, Complications of pregnancy" Ed: Davinsky O, Feldmann E, Hainline B, and Pub Raven Press NYY, 1994; 1-23.

[8]. Schaller B, Graf R. Cerebral venous infarction: the pathophysiological concept. Cerebrovasc .Dis.2004; 18(3):179-88.Epub 2004.

[9]. Banerjee AK, Chopra JS, Saw hney BB. Puerperal cerebral venous Thrombosis. Study of autopsy material .Neurology India 1973; 21:19-22.

[10]. Ameri A, Bousser MG. Cerebral venous Thrombosis. Neurology Clinics 1992; 10:87-111.

[11]. Deschiens MA, Conard J, Horellou MH Ameri A, Preter M,Chedru F et al,Coagulation studies ,Factor V Leiden and anticardiolipin antibodies in 40 cases with cerebral venous thrombosis. Stroke 1996; 27:1724-1730.

[12]. Rosendaal FR: Venous Thrombosis, a multicausal disease. Lancet 1999; 353:1167-1173.

[13]. Ahmad A, Genetics of Cerebral Venous Thrombosis. Journal of Pakistan Medical Association 2006; 11:488-490.

[14]. Rooper A H, Brown R H .Adams and Victor's Principles of Neurology. Eighth edition New York: Mc Graw - Hill; 2005.

[15]. Bertina RM, Koeleman BPC, Koster T. Mutation in blood coagulation factor V associated with resistance to activated protein C. Nature 1994; 369:64-66.

[16]. Kalafatis M, Bertina RM, R and MD, Mann KG, Characterisation of the molecular defect in factor VR506q.J Biol Chem 1995; 270(8):4053-7.

[17]. Shen L, Dahlback B, Factor V and protein S as synergistic cofactors to activated protein C in degradation of factor VIII a.J Biol Chem 1994;269(29):18735-18737.

[18]. Khan S, Dickerman JD. Hereditary thrombophilia. Thrrombosis Journal 2006;4:117.

[19]. Poort SR, Rosendaal FR, Reitsma PH, Bertina RM.A Common genetic variation in the 3'untranslated region of the prothrombin gene is associated with elevated plasma prothrombin levels and an increase in venous thrombosis. Blood 1996;10:3698-3703.

[20]. Foster DC, Yoshitake S, Davie EW.The nucleotide sequence of the gene for Human Protein $c$,Proc Natl Acad Sci 1985;82(14):4673-7.

[21]. Reitsma PH , Bernardi F, Doig RG. Protein C deficiency :A database of Mutations, 1995 update.Thrombosis and Haemostasis $1995 ; 73: 876$.

[22]. Lensen R P, Rosendaal FR, Koster T, Allaart CF , de Ronde H, Vandenbroucke JP et al, Apparent different thrombolytic tendency in patients with factor V Leiden and Protein C deficiency due to selection of patients .Blood 1996;88(11):4205-4208.

[23]. Schmidel DK , Tatro AV, Phelps LG, Tomczak JA, Long GL, Organization of the human protein S genes .Biochemistry 1990;29(34):7845-7852.

[24]. Simmond's RE, Ireland H, Kunz G, Lane DA. Identification of 19 protein SS gene mutations in patients with phenotypic protein S deficiency and thrombosis_-Protein S Study Group Blood 1996;88(11):4195-4204.

[25]. Gandrille S, Borgel D, Eschwege - Gubblet V, Ailand M,Dreyfus M, Matheron C et al. Identification of 155 different candidates causal point mutations and three polymorphisms in 19 patients with protein S active gene, Blood 1995;85(1):130-138.

[26]. Zoller B, Svensson PJ, He X, Dahlback B. Identification of the same factor V mutation in 47 out of 60 thrombosis- prone families with inherited resistance to activated protein C ,J Clin Invest 1994;94:2521 - 2524.

[27]. Lijnen HR, Soria J, Soria C. Dysfibrinogenemia associated with impaired fibrin- enhanced plasminogen activation. Thrombosis and Haemostasis 1984; 51:108.

[28]. KosterT, BlannAD, BrietE, VandenbrouckeJP, RosendaalFR.Roleofclotting Factor VIIIineffectofvon Willebrand factoronoccurrenceofdeep-vein thrombosis.Lancet1995; 345:152-155. 